\title{
Invited review: Current production trends, farm structures, and economics of the dairy sheep and goat sectors
}

\author{
G. Pulina, ${ }^{\star}$ M. J. Milán,† M. P. Lavín,‡ A. Theodoridis,§ E. Morin,\# J. Capote,Il D. L. Thomas,ף \\ A. H. D. Francesconi, ${ }^{* 1}$ and G. Caja† \\ *Department of Agricultural Science, University of Sassari, Sassari 07100, Italy \\ †Group of Research in Ruminants (G2R), Department of Animal and Food Sciences, Universitat Autònoma de Barcelona, Bellaterra 08193, Spain \\ łInstituto de Ganadería de Montaña, Consejo Superior de Investigaciones Científicas (CSIC), Grulleros 24346, León, Spain \\ $\S$ Laboratory of Animal Production Economics, Faculty of Veterinary Medicine, Aristotle University of Thessaloniki, Thessaloniki 54124, Greece \\ \#lnstitut de l'Élevage, Castanet Tolosan 31321, France \\ $\|$ Canary Islands Institute of Agricultural Research (ICIA), La Laguna 38200, Tenerife, Spain \\ IDepartment of Animal Sciences, University of Wisconsin-Madison, Madison 53706
}

\begin{abstract}
Dairy small ruminants account for approximately $21 \%$ of all sheep and goats in the world, produce around $3.5 \%$ of the world's milk, and are mainly located in subtropical-temperate areas of Asia, Europe, and Africa. Dairy sheep are concentrated around the Mediterranean and Black Sea regions, where their dairy products are typical ingredients of the human diet. Dairy goats are concentrated in low-income, fooddeficit countries of the Indian subcontinent, where their products are a key food source, but are also present in high-income, technologically developed countries. This review evaluates the status of the dairy sheep and goat sectors in the world, with special focus on the commercially and technically developed industries in France, Greece, Italy, and Spain (FGIS). Dairy small ruminants account for a minor part of the total agricultural output in France, Italy, and Spain (0.9 to 1.8\%) and a larger part in Greece (8.8\%). In FGIS, the dairy sheep industry is based on local breeds and crossbreeds raised under semi-intensive and intensive systems and is concentrated in a few regions in these countries. Average flock size varies from small to medium (140 to 333 ewes/farm), and milk yield from low to medium ( 85 to $216 \mathrm{~L} /$ ewe), showing substantial room for improvement. Most sheep milk is sold to industries and processed into traditional cheese types, many of which are Protected Denomination of Origin (PDO) cheeses for gourmet and export markets (e.g., Pecorino, Manchego, and Roquefort). By comparing break-even milk price among FGIS countries, we observed the following: (1) most Greek and French dairy sheep farms were
\end{abstract}

Received October 18, 2017.

Accepted April 19, 2018.

${ }^{1}$ Corresponding author: france@uniss.it unprofitable, with the exception of the intensive Chios farms of Greece; (2) milk price was aligned with cost of production in Italy; and (3) profitable farms coexisted with unprofitable farms in Spain. In FGIS, dairy goat production is based on local breeds raised under more extensive systems than sheep. Compared with sheep, average dairy goat herds are smaller (36 to 190 does/ farm) but milk yield is greater (153 to $589 \mathrm{~L} /$ doe), showing room for improvement. Goat milk is mainly processed on-farm into dairy products for national markets, but some PDO goat milk cheeses (e.g., Murcia al Vino) are exported. Processed goat milk is sold for local human consumption or dehydrated for export. Mixed sheep-goat (e.g., Feta) and cow-sheep-goat milk cheeses are common in many countries. Strategies to improve the dairy sheep and goat sectors in these 4 countries are proposed and discussed.

Key words: milk, dairy sheep, dairy goat, production system

\section{INTRODUCTION}

There are approximately 2,200 million sheep and goats in the world, and $20.8 \%$ are intended for dairy production (Table 1). Despite this large number of animals, sheep and goat milk represented only 1.3 and $1.9 \%$, respectively, of the world's total milk production in 2016 (799 Mt). Cattle (83.1\%) and buffaloes (13.1\%) are the most important milk producers, and camel milk accounts for only $0.3 \%$ of world milk production (FAOSTAT, 2018). Nevertheless, worldwide sheep and goat milk production has more than doubled during the last $50 \mathrm{yr}$ and, if this trend is maintained, it is expected to increase by approximately $2.7 \mathrm{Mt}(+26 \%)$ and $9.7 \mathrm{Mt}$ $(+53 \%)$, respectively, by 2030 (Figure 1). Taking into account the total solids content of all products from dairy sheep (i.e., milk, meat, and wool) and dairy goats 
Table 1. World panorama of dairy sheep and goats ${ }^{1}$

\begin{tabular}{|c|c|c|c|c|c|c|c|c|}
\hline Continent & \multicolumn{2}{|c|}{ Total $^{2}[$ million head (\%)] } & \multicolumn{2}{|c|}{ Dairy [million head (\%)] } & \multicolumn{2}{|c|}{$\operatorname{Milk}[\operatorname{Mt}(\%)]$} & \multicolumn{2}{|c|}{ Yield $^{3}[\mathrm{~L} /$ head $]$} \\
\hline$\overline{\text { Asia }}$ & $512(43.6)$ & $556(55.4)$ & $135(54.0)$ & $106(52.1)$ & $4.73(45.6)$ & $8.04(52.7)$ & 35.1 & 76.2 \\
\hline Europe & $131(11.2)$ & $17(1.7)$ & $33(13.3)$ & $9(4.3)$ & $3.01(29.0)$ & $2.54(16.6)$ & 90.8 & 290.1 \\
\hline America & $84(7.1)$ & $38(3.8)$ & $3(1.1)$ & $8(4.0)$ & $0.09(0.9)$ & $0.75(4.9)$ & 33.0 & 93.4 \\
\hline Oceania & $95(8.1)$ & $4(0.4)$ & $<0.1(0)$ & $<0.1(0)$ & $<0.01(0)$ & $<0.01(0)$ & - & - \\
\hline
\end{tabular}

${ }^{1}$ Source: FAOSTAT (2018).

${ }^{2}$ Total number of sheep and goats (regardless of purpose).

${ }^{3}$ The last row for yield is the mean rather than the total.

(i.e., milk and meat, the production of fiber being negligible; FAOSTAT, 2018) worldwide, we estimate that the ratio of milk:meat:wool in dairy sheep is $28: 45: 27$ (38:62 milk:meat, without wool), whereas the milk: meat ratio in dairy goats is $58: 42$.
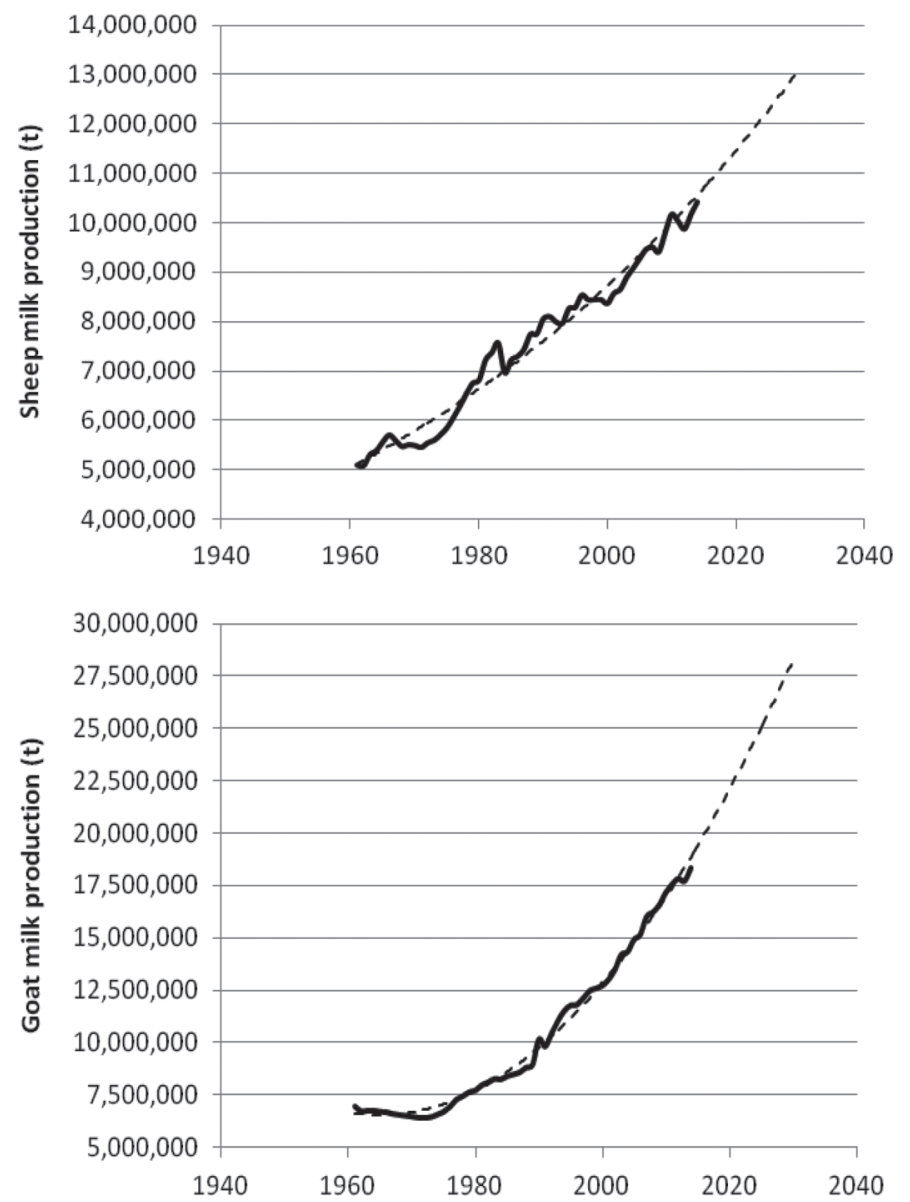

Figure 1. World sheep and goat milk production trends from 1960 to 2016 (solid line) and forecast to 2030 by using time-series model (dashed line) (FAOSTAT, 2018).
Dairy sheep and goat farms are mainly located in subtropical-temperate areas of Asia, Europe, and Africa. Dairy sheep are concentrated in countries in the Mediterranean and Black Sea regions with relevant Greek or Roman cultural heritage (Caja, 1990), where dairy products are typical ingredients of the human diet. Dairy goats are concentrated in the Indian subcontinent in low-income, food-deficit countries, where their products are a primary food source, but are also present in high-income and technologically developed countries.

Compared with milk of dairy cows, that of small ruminants is generally not consumed directly but is used in the production of niche or ethnic dairy foods, usually used for self-consumption or sold as traditional and high-quality dairy products (e.g., Feta cheese and yogurt) included in the list of key ingredients of the so-called Mediterranean diet (Dennett, 2016).

Given the growing importance of the sheep and goat dairy industry in the world, this paper aims to describe the current production trends, farm structures, and economic results of the dairy sheep and goat sectors, with special attention to the European Mediterranean countries where they are currently most developed (i.e., France, Greece, Italy, and Spain).

\section{WORLD PANORAMA OF DAIRY SHEEP AND GOATS}

\section{Dairy Sheep}

According to FAOSTAT (2018), sheep milk (10.4 Mt) is mainly produced in Asia (45.6\%), with remarkable amounts in China and Turkey, followed by Europe $(29.0 \%)$ and Africa (24.5\%; Table 1). Additionally, there is a very small but growing production in the North and South Americas $(0.9 \%)$ and Oceania $(<0.1 \%)$.

Most world dairy sheep are raised in an area bounded by the $35^{\circ} \mathrm{N}$ and $45^{\circ} \mathrm{N}$ parallels and the $20^{\circ} \mathrm{W}$ and $50^{\circ} \mathrm{E}$ meridians. Curiously, new dairy sheep areas are still 
located in the $35^{\circ}$ to $45^{\circ} \mathrm{N}$ belt, regardless of meridian or hemisphere (e.g., Wisconsin and New York in the United States; Argentina; New South Wales in Australia; and New Zealand).

On average, milk yield is low in Asia, Africa, and America (32 to $35 \mathrm{~L} /$ ewe per yr; Table 1). Although few data are available on dairy sheep production in China, sheep milk is currently growing in that country and is mainly used for home consumption and production of organic milk and infant formulas, many of which have been developed in joint ventures with New Zealand companies. Milk yield of dairy ewes in Europe (91 L/ewe; Table 1) is more than double the world's average milk yield, showing the growth potential of the world dairy sheep sector. Countries bordering the Mediterranean and Black Sea regions have $27.1 \%$ of the ewes and produce $41.4 \%$ of the world sheep milk, with Turkey (21.6\%; 60 L/ewe), Greece (16.6\%; 106 L/ewe), Syria (15.2\%; 56 L/ewe), Romania (14.7\%; 89 L/ewe), and Spain $(12.6 \%$; $243 \mathrm{~L} /$ ewe) being the current leaders, followed by Italy $(9.9 \%$; $82 \mathrm{~L} /$ ewe), France $(6.8 \%$; $239 \mathrm{~L} /$ ewe), and Algeria (6.6\%; $26 \mathrm{~L} /$ ewe). Calculated individual milk yield clearly indicates the level of dairy specialization of the sheep industries in each country but is also related to the sheep breed used. In this regard, all the yield data given in this review for a breed come from the official performances reported by International Committee for Animal Recording (ICAR) for dairy sheep of all ages (ICAR, 2018a), unless otherwise indicated.

Although few data on the Romanian dairy sheep industry are available, the other 4 European Union (EU) countries (i.e., France, Greece, Italy, and Spain, hereafter FGIS) produce $45.8 \%$ of the total sheep milk from the Mediterranean and Black Sea regions and $12.9 \%$ of the world's sheep milk (FAOSTAT, 2018).

It is important to highlight that, despite maintaining traditional and local approaches, FGIS have developed modern dairy sheep systems characterized by specialized dairy breeds, technically advanced farms, and commercial processing plants that transform most of the milk into cheese (>90\%) and yogurt. Protected Designation of Origin (PDO) sheep-milk cheeses recognized by the EU play a major role in the international cheese trade and have a growing international market. The advanced technological level of the dairy industries in FGIS is also supported by the fact that more than $42 \%$ of the retrieved research publications on dairy sheep originated in these countries (i.e., search in the Scopus database using "dairy sheep" or "dairy ewes" as keywords).

The global export of sheep-milk cheese accounted for approximately US $\$ 374 \mathrm{M}$ in 2013 (FAOSTAT, 2018). Italy is the leader in sheep-milk cheese exports, holding
$36 \%$ of the market share, followed by France (20\%). The United States and Germany are the main importers, accounting for 42 and $41 \%$, respectively, of the total amount of sheep cheese imports (FAOSTAT, 2018). Cheeses imported by the United States and labeled as PDO sheep cheese are mostly from Italy, but significant imports also come from Spain, Greece, France, and Bulgaria (USDA-FAS, 2016). Despite the large commercial demand for sheep-milk cheeses in the United States, the country has not succeeded in developing an important dairy sheep industry. Several attempts have been made to develop the US industry by importing East Friesian and Lacaune sheep and semen in 1993 and 1998, respectively, and Awassi later (Meisegeier, 2013; Thomas et al., 2014; Karras, 2017). However, the US dairy sheep industry is still very small and, so far, there are no organizations for the recording of pedigrees and performances for dairy sheep in the country.

\section{Dairy Goats}

FAOSTAT (2018) estimates that dairy goats produce approximately $50 \%$ more milk (1.47 times) than dairy sheep, despite having a smaller population $(81.2 \%$; Table 1$)$. World goat milk (15.3 Mt) is mainly produced in Asia $(52.7 \%)$, with remarkable amounts in the Indian subcontinent (i.e., India, Bangladesh, and Pakistan), followed by Africa (25.7\%), where Sudan and South Sudan are the most important milk producers. Europe (16.6\%) and America (4.9\%) contribute to the world goat milk production, whereas production in Oceania is still negligible $(<0.1 \%)$.

According to FAOSTAT (2018), most dairy goats (92\%) are raised in Asia (52.1\%) and Africa (39.6\%), with smaller numbers in Europe (4.3\%) and the Americas $(4.0 \%)$, and a negligible population in Oceania $(<0.1 \%)$. Dairy goats are mainly located in tropical and arid areas of the world, named by the Food and Agriculture Organization of the United Nations (FAO) as low-income, food-deficit countries, and which hold $61 \%$ of the world goats. Thus, goat production is related to the income level of a country, as their products are a primary food source, but they are also present in high-income and technologically developed countries.

The average milk yield of dairy goats worldwide is higher than that for dairy sheep, but it varies widely by continent ( 49 to $290 \mathrm{~L} /$ doe; Table 1), depending on breed specialization and technical level of the farms and dairy industry. Indian subcontinent countries raise $36.7 \%$ of the world dairy goats and produce $40.7 \%$ of the world's goat milk, with India $(60.6 \% ; 129 \mathrm{~L} /$ doe), Bangladesh (16.9\%; $37 \mathrm{~L} /$ doe), and Pakistan (13.3\%; $100 \mathrm{~L} /$ doe) being the leaders, although milk yields per doe are still low and show substantial room for improve- 
ment. In China, dairy goat production is increasing rapidly, producing near $2 \%$ of the world's goat milk and showing moderate milk yield (189 L/doe). Compared with that of other countries, the highest milk yield per doe is obtained in Europe, and is almost 4 times the average yield worldwide-Europe produces $16.6 \%$ of the world's goat milk with only $4.3 \%$ of the dairy goat population (Table 1).

Countries in the Mediterranean and Black Sea regions are less important for dairy goats than for dairy sheep. These countries raise $10.5 \%$ of the world's dairy goats and produce $19.1 \%$ of the world's goat milk (FAOSTAT, 2018). Among them, France $(20.7 \% ; 715$ L/doe), Spain (14.1\%; 328 L/doe), Greece (13.2\%; 134 $\mathrm{L} /$ doe), and Turkey (11.8\%; $73 \mathrm{~L} /$ doe) are the current leaders in goat milk production of the area, followed by the Russian Federation (8.6\%; 330 L/doe), Ukraine (7.8\%; $500 \mathrm{~L} /$ doe), and Algeria $(7.9 \% ; 85 \mathrm{~L} /$ doe). As for dairy sheep, the estimated individual milk yields from FAOSTAT (2018) data indicate the degree of dairy specialization of the goat industry in each country. However, the values reported by FAO need to be carefully considered in some cases. As can be seen from the values of goat milk estimated by experts of each country later in this review, the FAO appears to underestimate some values, such as Greek goat milk production. In addition, in this review, all yield data for goat breeds come from the official performance reported by ICAR in dairy goats of all ages (ICAR, 2018b).

Overall, FGIS produce $49.2 \%$ of the goat milk in the Mediterranean and Black Sea regions and 9.4\% of the world's goat milk (FAOSTAT, 2018). Participation of these 4 countries in the development of dairy goat knowledge is lower than that for dairy sheep and only $8.1 \%$ of research publications retrieved on dairy goats were produced in FGIS (i.e., search in the Scopus database using "dairy goat" as keyword).

In contrast to the dairy sheep industry in FGIS, most goat breeds are dual-purpose; only a few are specialized for milk production. Although most goat milk is used for cheese production, its consumption as whole milk and yogurt is also common. In China, a considerable amount of goat milk is currently used to make milk powder. In the United States, as in other developed countries, goat milk is consumed by people intolerant to cow milk or suffering from digestive disorders. Data on international trade of goat cheeses are not available, but it is noteworthy that almost $50 \%$ of PDO goat cheeses produced in Spain are exported worldwide.

\section{THE DAIRY SHEEP INDUSTRY IN FGIS}

\section{France}

In France, dairy sheep milk accounts for $0.4 \%$ of the total agricultural output (TAO) and $1.1 \%$ of the livestock output (LO; MAAF, 2017; INSEE, 2018). The French sheep sector is moderately large with a low dairy specialization (1.6 million head and 30\%, respectively; Table 2). Most dairy sheep farms are semiextensive and moderate yielding (165 L/ewe; Table 2), with their milk mainly collected by dairy industries to be processed into cheeses (Bellet et al., 2017). Milking season is mostly determined by the milk collection schedule of the dairy industries, which mainly operate from November to August and remain closed the rest of the year. After mid July, milk needs to be processed on-farm or by small and local dairy industries.

More than $85 \%$ of dairy sheep farms are located in mountainous areas, mainly in Massif Central, Pyrenees,

Table 2. Main data of dairy sheep farms in 4 European Union countries (averaged data from different sources from 2013 to 2015)

\begin{tabular}{lcccc}
\hline Item & France $^{1}$ & Greece $^{2}$ & Italy $^{3}$ & Spain $^{4}$ \\
\hline Total sheep (million head) & 7.20 & 9.50 & 7.28 & 16.03 \\
Total ewes (million head) & 5.40 & 6.18 & 6.31 & 12.41 \\
Dairy ewes (million head) & 1.60 & 5.74 & 4.70 & 2.65 \\
Dairy specialization (\%) & 29.6 & 93.0 & 74.5 & 21.3 \\
Dairy farms (no.) & 4,805 & 41,004 & 29,182 & 18,266 \\
Milk production (ML) & 263.8 & 580.3 & 397.5 & 571.0 \\
Dairy ewes/farm (no.) & 333.0 & 140.1 & 161.1 & 144.9 \\
Milk yield (L/ewe) & 164.9 & 101.0 & 84.6 & 215.8 \\
AWU /farm (no.) & 1.5 & 1.5 & 1.2 & 1.3 \\
Ewes/AWU (no.) & 222.0 & 93.4 & 134.2 & 11.4 \\
Milk price (€/L) & 0.962 & 0.957 & 0.950 & 0.931 \\
\hline
\end{tabular}

${ }^{1} \operatorname{IDELE}(2016 \mathrm{a})$ and MAAF (2017).

${ }^{2}$ ELOGAK (2017).

${ }^{3}$ ISTAT (2017a).

${ }^{4}$ MAPAMA (2016a,b).

${ }^{5}$ Annual work unit. 
and Corsica, where local sheep breeds are raised under seasonal production systems. Ewes of the high-yielding Lacaune breed (289 L/ewe) produce milk for the Roquefort (blue cheese) industry of the southern Massif-Central, being kept indoors from autumn to spring and grazing pastures and rangelands during the rest of the year. Lacaune lambs are sold as milk-fed lambs or after a 3-mo fattening period. Moderate-yielding Pyrenean sheep breeds (i.e., Basco-Bearnaise, Manech Black or Red Faced; 151 to 209 L/ewe), from the Western Pyrenees produce milk for Ossau-Iraty (hard cheese). The small and low-yielding Corsa breed (137 L/ewe) is extensively reared in the mountains of Corsica, where Brocciu (whey cheese) is made. In the Pyrenees and Corsica, lambs are mainly sold as milk-fed lambs and ewes graze natural pastures year round and often spend the summer on the mountains (Champion et al., 2013). Efficient breeding schemes have been in place for the last $50 \mathrm{yr}$ for French dairy sheep breeds, thus improving milk yield and composition and udder morphology (Barillet et al., 2016).

Slightly more than half of all French sheep farms specialize in dairy, with greater percentages in Roquefort $(70 \%)$ and Corsica (65\%). Corsica accounts for only $4 \%$ of all French sheep milk, whereas Roquefort and Pyrenees together account for $88 \%$ (Champion et al., 2013). According to data from the French Livestock Network, sales of sheep milk are the main source of income for dairy sheep farms, contributing to $68 \%$ (Roquefort) or $73 \%$ (Pyrenees) of gross output, whereas the sales of lambs represent only 23 and $16 \%$ of the gross output, respectively, in these regions (Table 3). Production costs of sheep farms are similar in both locations, with feeding costs being the most important cost (45\%), followed by labor (Table 3). No similar information is available for Corsica. Average sheep milk price paid to farmers by the dairy industry increased by only $12 \%$ in the last decade (i.e., from $€ 0.871 / \mathrm{L}$ in 2004 to $€ 0.975 / \mathrm{L}$ in 2015; IDELE, 2017).

An important economic criterion to evaluate the dairy sheep industry of each country is the break-even point (i.e., when gross revenue equals total cost), which, in the case of France, ranged between $€ 1.28 / \mathrm{L}$ of milk for Roquefort and $€ 1.76 / \mathrm{L}$ for the Western Pyrenees (Table 3).

On-farm cheese production is not a common practice in French dairy sheep farms (6\% of sheep milk). However, this practice is quite frequent in Western Pyrenees and Corsica, where 15 and $30 \%$ of farmers, respectively, make a living by producing and selling homemade sheep cheeses (Champion et al., 2013). Production of the 3 PDO sheep cheeses (Roquefort, Ossau-Iraty, and Brocciu) accounts for $35 \%$ of total sheep cheese production in France (Creusat et al., 2015). More than 20\% of Roquefort cheese was exported in 2015, mainly to the rest of the EU (Bellet et al., 2017).

\section{Greece}

Greek dairy sheep milk contributes $9.4 \%$ to the TAO and $43 \%$ to the LO (ELOGAK, 2017; ELSTAT, 2017). The Greek sheep sector has the highest dairy specialization $(93 \%)$ and leads sheep milk production in the EU (Table 2). Sheep milk is mainly used for the production of Feta, a PDO cheese that is made of sheep milk or of a mixture of sheep and goat milk (but always $>70 \%$ sheep milk) and is the most important export product of the Greek primary sector.

The Greek sheep farming sector shows a large diversity of production systems (i.e., extensive-transhumant, semi-extensive, and intensive). Extensive farms have limited use of purchased inputs or fixed capital, ap-

Table 3. Economic data and break-even milk price for dairy sheep farms in France (average results from 2013 to 2015$)^{1}$

\begin{tabular}{|c|c|c|c|c|}
\hline \multirow[b]{2}{*}{ Item } & \multicolumn{2}{|c|}{ Roquefort } & \multicolumn{2}{|c|}{ Western Pyrenees } \\
\hline & $€ / 1,000 \mathrm{~L}$ & $\%$ & $€ / 1,000 \mathrm{~L}$ & $\%$ \\
\hline Gross revenue & 1,339 & & 1,414 & \\
\hline Milk & 913 & 68 & 1,028 & 73 \\
\hline Lambs and cull ewes & 302 & 23 & 230 & 16 \\
\hline Other products & 21 & 2 & 4 & $<1$ \\
\hline $\mathrm{CAP}^{2}$ coupled subsidies & 103 & 8 & 152 & 11 \\
\hline Costs of production & 1,705 & & 2,150 & \\
\hline Family and hired labor costs & 467 & 27 & 642 & 30 \\
\hline Feeding system costs & 762 & 45 & 961 & 45 \\
\hline Equipment and depreciation & 251 & 15 & 250 & 12 \\
\hline Other costs & 225 & 13 & 296 & 14 \\
\hline Break-even milk price & 1,279 & & 1,763 & \\
\hline
\end{tabular}


Table 4. Economics of Greek dairy sheep farms according to production system

\begin{tabular}{|c|c|c|c|c|}
\hline \multirow[b]{2}{*}{ Item } & \multicolumn{2}{|c|}{ Intensive $^{1}$} & \multicolumn{2}{|c|}{ Extensive $^{2}$} \\
\hline & $€ /$ ewe & $\%$ & $€ /$ ewe & $\%$ \\
\hline \multicolumn{5}{|l|}{ Incomes } \\
\hline Milk & 189 & 46.2 & 79 & 56.0 \\
\hline Cheese or wool & - & - & 7 & 5.0 \\
\hline Meat & 154 & 37.7 & 40 & 28.4 \\
\hline Subsidies & 27 & 6.6 & 15 & 10.6 \\
\hline Agriculture & 39 & 9.5 & - & - \\
\hline Total incomes & 409 & 100.0 & 141 & 100.0 \\
\hline \multicolumn{5}{|l|}{ Expenses } \\
\hline Land cost & 32 & 7.9 & 6 & 3.5 \\
\hline Labor cost & 67 & 16.4 & 45 & 26.3 \\
\hline Capital cost & 307 & 75.7 & 120 & 70.2 \\
\hline Variable capital cost & 194 & 47.9 & 99 & 57.9 \\
\hline Purchased feed & 125 & 30.8 & 70 & 40.9 \\
\hline Miscellaneous $^{3}$ & 27 & 6.7 & 26 & 15.2 \\
\hline Crop production expenses & 42 & 10.4 & 3 & 1.8 \\
\hline Fixed capital cost & 113 & 27.9 & 21 & 12.3 \\
\hline Total expenses & 406 & 100.0 & 171 & 100.0 \\
\hline
\end{tabular}

ply traditional management and feeding practices (i.e., grazing), and have low productivity. These farms coexist with intensive ones, which are capital intensive (i.e., high investment in facilities and equipment) and large users of purchased feed, with the aim of maximizing milk yield and farm profit.

Most Greek dairy sheep are the medium-yielding local breeds Karagouniko (143 L/ewe), mainly raised in Central Greece (Thessaly); Lesvou (157 L/ewe), the most numerous dairy breed, raised on the island of Lesvos; and the high-yielding Chios breed (303 L/ ewe), raised all over the country. New breeds, such as Frizarta (234 L/ewe), were produced in the 1960s by crossbreeding local breeds with rams of high-yielding imported breeds (i.e., East Friesian), and are currently raised in the region of South Epirus (Kominakis et al., 2017). Recently, the high-yielding Assaf breed has been introduced into Greece from Spain. Most lambs are sold as milk-fed lambs.

The circumstances shaped by the current economic crisis, such as high input prices, low milk prices, and financial stress, have severely affected the Greek dairy sheep sector, threatening mainly the intensive farms. An economic comparison between intensive and extensive (transhumant) dairy sheep farms in Greece, as reported by Ragkos et al. (2014) and Theodoridis et al. (2014), is shown in Table 4. Milk sales accounted for approximately half of the incomes in both types of farms (46.2 to $56.0 \%$ ), followed by lamb sales (28.4 to $37.7 \%$ ), which were usually greater in intensive farms due to the sales of breeding stock (i.e., Chios purebred). Value of EU subsidies (6.6 to 10.6\%) indicated a non- trivial dependence of the farms on the EU's Common Agricultural Policy (CAP). Incomes of intensive farms were almost triple that of extensive farms, with their total expenses accounting for 99 and $121 \%$ of gross incomes, respectively (Table 4). As expected, purchased feedstuffs in intensive farms were almost twice that of extensive farms (€125/ewe vs. €70/ewe; Table 4). As a result, the gross margin calculated from Table 4 (i.e., total incomes minus variable capital costs) was €215/ ewe and $€ 42 /$ ewe for intensive and extensive farms, respectively. The partitioning of the production cost of extensive farms confirmed that such farms were labor dependent (26.3\%) and not fixed-capital intensive (Ragkos et al., 2014; Table 4). Consequently, these farms were less vulnerable to volatile economic conditions and survived during periods of financial stress, mainly due to their low capital endowments and intensive use of family labor.

Greek sheep-milk prices during the last decade were, on average, constant and high (€0.951/L), with the price paid to farmers by the dairy industries remaining steady during the last decade (i.e., €0.9350/L in 2008 and $€ 0.9346 / \mathrm{L}$ in 2017). The estimated breakeven point for Greece was €0.85/L of milk for intensive Chios farms and $€ 1.14 / \mathrm{L}$ for extensive farms (transhumant flocks).

\section{Italy}

Dairy sheep milk contributed $0.7 \%$ to Italy's TAO and $2.4 \%$ to LO (ISTAT, 2017a,b). Dairy sheep account for $75 \%$ of all Italian sheep, with the sector being 
characterized by semi-extensive farms using natural pastures as the main feeding source. Grazing is seasonal and varies with farm location and altitude. It can be concentrated in winter-spring (e.g., southern Italy and lowlands) or in autumn-late spring (e.g., northern Italy and highlands). For this reason, the length of the milking season ranges from 150 to $250 \mathrm{~d}$, except for intensive farms, and the dry period is longer than that observed in dairy cattle and goats. Approximately 4.7 million dairy ewes are reared and $397.5 \mathrm{kt}$ of sheep milk are produced annually in Italy (ISTAT, 2017a). The number of dairy ewes decreased gradually over the last decade $(-1.15 \%$ per yr) and dramatically in $2015(-0.5$ million) because of a severe outbreak of blue-tongue disease. In the same period, the amount of sheep milk decreased by only $0.6 \% / \mathrm{yr}$ but reached the lowest yield (85 L/ewe) among FGIS.

Dairy ewes are mainly located in the islands of Sardinia $(21.8 \%)$ and Sicily (11.3\%), and in central Italy (i.e., Tuscany, Umbria, Marche, Lazio, and Abruzzo regions), together accounting for $21.8 \%$ of total dairy sheep. Among these regions, milk is mainly produced in Sardinia (65.6\%), Tuscany $(14.5 \%)$, Lazio $(7.9 \%)$, and Sicily $(6.5 \%)$ by the following 4 local moderate- and high-yielding dairy breeds: Sarda (80\%; $201 \mathrm{~L} /$ ewe), reared in Sardinia, Tuscany, and Lazio; Comisana (13\%; $159 \mathrm{~L} /$ ewe) and Valle del Bellice (3\%; $163 \mathrm{~L} /$ ewe) in Sicily; and Massesse (4\%; 129 L/ewe) in Tuscany.

The main income in Italian dairy sheep farms comes from milk $(72 \%)$, followed by milk-fed or light lamb sales $(21 \%)$, and subsidies (7\%). The main component of costs is farm labor (38\%), followed by variable costs (29\%), partitioned into feeding costs and other variable costs (77 and 33\%, respectively). Assuming a normal distribution, the production costs of Italian dairy sheep farms ranged between $80 \%$ and $120 \%$ of gross income. Milk price varied considerably in recent years, increasing from $€ 0.85 / \mathrm{L}$ in 2014 to $€ 1.05 / \mathrm{L}$ in 2016 and then decreasing dramatically to $€ 0.70 / \mathrm{L}$ in 2017 . The breakeven point estimated for Italian dairy sheep farms was $€ 0.95 / \mathrm{L}$ of milk.

Most Italian sheep milk is processed by the dairy industry $(71 \%)$ and the rest $(29 \%)$ is transformed into dairy products on the farm (ISTAT, 2017a). Approximately $30 \%$ of Italian sheep milk is used for the production of the PDO cheese Pecorino Romano, which is the main sheep cheese produced in Italy and the leader in the international trade of sheep-milk cheeses. Historically, the price of Pecorino Romano regulated the price of sheep milk in Italy. For many years, there was a lag of approximately $1 \mathrm{yr}$ between the price of cheese and that of milk paid to farmers, but both prices are currently tightly coupled (ISMEA, 2017; Figure 2). The cyclic fluctuations in the price of sheep milk sold for the production of Pecorino Romano, observed for more than a century, were due to the well-known economic phenomenon of overproduction following a period of high market prices (i.e., the cobweb model). This evolution pattern revealed a lack of market strategy and the prevalence of speculation rather than the application of a policy able to maintain cheese production under a threshold. The price of Pecorino cheese in the international market has varied considerably over time, increasing by $77 \%$ in the last decade (i.e., from $€ 5.2 / \mathrm{kg}$ in 1995 to $€ 9.2 / \mathrm{kg}$ in 2015 ) but decreasing by $11 \%$ in 2016 (ISMEA, 2017). On the other hand, the amount of Pecorino Romano cheese imported by the United States decreased $35 \%$ in the last decade (i.e., from $29 \mathrm{kt}$ in 1995 to $19 \mathrm{kt}$ in 2015) due to the increase in cow cheese stocks in the United States and the concurrence with other sheep cheese FGIS exporters (i.e., Spain).

\section{Spain}

Milk of dairy sheep contributed $1.2 \%$ to the TAO and $3.2 \%$ to the LO of Spain from 2013 to 2015 (MAPAMA, 2016b). After the United Kingdom, which should leave the EU in 2019, Spain has the second largest sheep population in the EU. Spain is also second in sheep milk production in the EU. Nevertheless, dairy sheep account for only $21 \%$ of Spanish sheep (Table 2), with the remainder intended for lamb production. The large amount of sheep milk produced in Spain $(571.0 \mathrm{kt})$ is mainly a result of the high yield obtained per ewe (Table 2).

Most sheep milk (94.1\%) is produced in the Northern (Castilla y León, 60.2\%; Navarra, 2.2\%; Basque Country, 1.8\%) and Central (Castilla-La Mancha, 27.9\%; Extremadura, 2.0\%) Autonomous Communities of Spain. Specialized dairy breeds are raised and milk-fed lambs are produced in northern farms, whereas dual-purpose breeds and fattening lambs predominate in central and southern farms.

Spanish dairy sheep farms are, on average, small (145 ewes; Table 2), but farm size is heterogeneous. In fact, $78.8 \%$ of milk production is concentrated in $24.5 \%$ of the farms because of a deep restructuring of the sector in recent years. During the last decade, $28.3 \%$ of dairy sheep farms and $32.3 \%$ of dual-purpose farms (i.e., $13.9 \%$ dairy ewes) left the dairy industry, resulting in a noticeable depopulation of rural areas in the Northern and Central Autonomous Communities (MAPAMA, 2016a). Despite this, sheep milk production increased $36.4 \%$ during the same period, reaching $216 \mathrm{~L} /$ ewe on average (Table 2), due to substantial improvements in production systems (i.e., feeding, genetics, management, and facilities), as reported by Milán et al. (2011). One of the reasons for the rapid increase in sheep milk pro- 
duction in Spain during the last 30 yr was the introduction of high-yielding foreign breeds, used as purebreds or crossbreds, into traditional production systems. The main foreign breeds are Assaf (400 L/ewe), found primarily in Castilla y León (Ugarte et al., 2001; Milán et al., 2011), and Lacaune (350 L/ewe), which are widely spread across the country. High-yielding ewes from foreign breeds coexist with local breeds with their own effective genetic selection schemes (Manchega, 190 L/ewe; Latxa, 168 L/ewe; Churra, 117 L/ewe), all of which are raised under intensive systems, or with other local breeds raised under traditional dual-purpose, semi-extensive systems (i.e., Talaverana and Merina). Intensification of traditional production systems has been associated with the enlargement of dairy flocks, reduction in grazing, and increase in labor specialization (Mantecón et al., 2009), with consequent increases in feeding expenditures and facilities investment.

In Spain, incomes and costs of dairy sheep farms markedly vary with production system and Autonomous Community. For intensive dairy sheep farms of Castilla y León, Milán et al. (2014) reported that milk sales were the main income source $(78.6 \%)$, followed by milk-fed lamb sales (13.2\%), and EU subsidies (6.9\%), whereas the main costs were feeding $(61.6 \%$; ranging from 57 to $68 \%$ ), labor (18.2\%), and equipment maintenance and depreciation (7.6\%). Milán et al. (2014) calculated a mean profitability of $€ 7.4 /$ ewe, ranging from - $€ 40.6$ /ewe to $€ 81.1$ ewe among farms. Breakeven points were 383 ewes/flock, $291 \mathrm{~L} /$ ewe, 250 ewes/ animal work unit (AWU), and a price of $€ 0.798 / \mathrm{L}$ of milk.

Sheep milk prices have fluctuated dramatically in recent years in Spain. The strong increase $(22.8 \%)$ observed from 2005 to 2015 (from €0.791/L to €0.971/L) supported the expansion of the Spanish sheep industry during the recent economic crisis (MAPAMA, 2016a). However, since 2016, the milk price (€0.885/L) has declined enough to threaten the survival of less competitive dairy sheep farms. Given the considerable diversity of dairy sheep production systems that coexist in Spain, the estimated break-even point for different types of dairy sheep farms ranged between $€ 0.6 / \mathrm{L}$ and $€ 1.1 / \mathrm{L}$ of milk.

Most Spanish sheep milk is processed into hard cheeses in large and local dairy industries (93.9\%; MAPAMA, 2016a) and the rest is processed in artisanal dairies (self-consumption, $2.6 \%$; direct sales, $3.5 \%$ ) that produce recognized labeled products, usually destined for local markets. In contrast, more than half $(53.6 \%)$ of the milk produced in dairy sheep farms of the Basque Country is processed and sold on the farm.

Among FGIS, Spain is a low consumer of cheese (9.6 $\mathrm{kg} /$ inhabitant), with a very low level of self-supply and high potential for increasing consumption in the future. A typical aspect of the Spanish dairy sector is blending

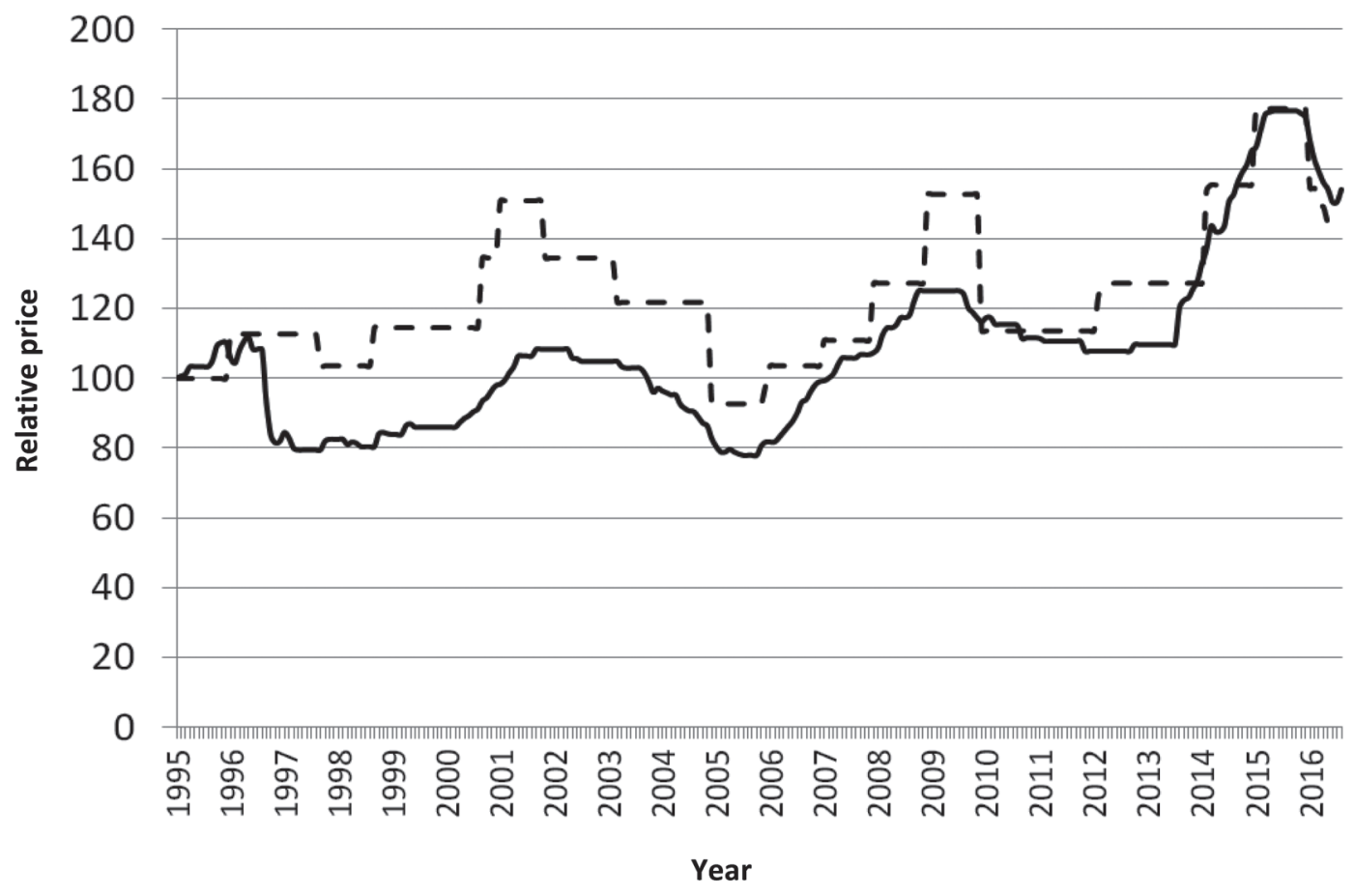

Figure 2. Changes in the relative prices of Pecorino Romano cheese (dashed line) and sheep milk paid to farmers (solid line) in Italy (1995 = index 100; ISMEA, 2017). 
Table 5. Main features of dairy goat farms in 4 European Union countries (averaged data from 2013 to 2015)

\begin{tabular}{lcccc}
\hline Item & France $^{1}$ & Greece $^{2}$ & Italy $^{3}$ & Spain $^{4}$ \\
\hline Total goats (million head) & 1.30 & 4.20 & 1.04 & 2.80 \\
Total does (million head) & 1.10 & 2.75 & 0.80 & 1.94 \\
Dairy does (million head) & 1.00 & 2.40 & 0.75 & 1.11 \\
Dairy specialization (\%) & 90.9 & 87.3 & 93.7 & 57.1 \\
Dairy farms (no.) & 5,263 & 14,973 & 21,111 & 17,439 \\
Milk production (ML) & 589.3 & 600.0 & 115.2 & 466.6 \\
Dairy does/farm (no.) & 190.0 & 160.2 & 35.5 & 63.5 \\
Milk yield (L/doe) & 589.3 & 250.0 & 153.3 & 421.5 \\
AWU /farm (no.) & 1.7 & -6 & 0.4 & 1.3 \\
Does/AWU (no.) & 111.1 & - & 88.9 & 48.8 \\
Milk price (€/L) & 0.666 & 0.582 & 0.700 & 0.696 \\
\hline
\end{tabular}

${ }^{1} \operatorname{IDELE}(2016 \mathrm{~b})$ and MAAF (2017).

${ }^{2}$ ELOGAK (2017).

${ }^{3} \operatorname{ISTAT}(2017 \mathrm{a})$.

${ }^{4}$ MAPAMA (2016a,b).

${ }^{5}$ Annual work unit.

${ }^{6}$ Data not available.

of milk, which is especially appreciated for cheese-taste improvement, with some mixed-milk cheeses being PDO cheeses (e.g., Cabrales). Of the total amount of cheese (465.4 kt) produced in Spain, 37.8\% corresponds to cow-sheep-goat milk cheeses (e.g., Mezcla), with pure sheep-milk cheese accounting for only $74.6 \mathrm{kt}(16.1 \%)$ and its consumption being $0.38 \mathrm{~kg} / \mathrm{yr}$ per capita (3.9\%), as reported by MAPAMA (2016b). Despite this, Spain was the FGIS leader, accounting for $34.6 \%$ of the total pure sheep-milk cheese production in the EU in 2015. In Spain, $23.0 \%$ of pure sheep-milk cheese is sold as PDO sheep-milk cheese. Out of the 6 PDO sheep-milk cheeses produced in Spain, Manchego, from CastillaLa Mancha, is the most produced (85.4\%). The rest of the production is distributed among Idiazabal $(7.6 \%)$ from the Basque Country and Navarre; Roncal (2.3\%) from Navarra; Zamorano (2.2\%) from Castilla y León, and Torta del Casar (1.8\%); and De la Serena (0.7\%) from Extremadura. Fifty-four percent of Spanish PDO sheep-milk cheeses (9.3 kt) are exported, most of them outside the EU (58.0\%), with the United States being the main destination. In fact, Spain has recently become the second largest sheep-milk cheese exporter to the United States (USDA-FAS, 2016).

\section{THE DAIRY GOAT INDUSTRY IN FGIS}

\section{France}

Goat milk accounted for $0.5 \%$ of the TAO and $1.3 \%$ of the LO in France (MAAF, 2017; INSEE, 2018). France raises almost 1.0 million dairy goats, which produce $589.3 \mathrm{kt}$ of goat milk, with an average milk yield of 589 $\mathrm{L} /$ doe and a high degree of specialization $(91 \%$; average data from 2013 to 2015; Table 5). This yield value is much lower than the value of $715 \mathrm{~L} /$ doe previously reported in this review and calculated from FAOSTAT (2018), which likely underestimated the current dairy goat population in France.

French goat farmers raise mainly Alpine (886 L/doe) and Saanen (946 L/doe) breeds, which are adapted to a wide variety of production systems, mostly intensively and semi-intensively managed. In addition, local goat breeds such as Poitevine (516 L/doe), Pyrenean, or Corsica are raised in more extensive systems. Most goat herds are mid-sized (190 goats/herd; Table 5) although $77 \%$ of the farms have fewer than 100 goats, which graze on cultivated pastures or rangelands (Perrot et al., 2013).

Only half of French goat farms deliver their milk to the dairy industry. These farms produce large amounts of milk and are mainly located in the midwest and southwest of the country, where harvested forages allow farmers to intensify goat production $(77 \%$ of the herds graze fewer than $100 \mathrm{~d} / \mathrm{yr}$; Perrot et al., 2013). Nevertheless, only one-third of these farms are fully specialized in dairy goat production. The other twothirds not only have dairy goats but also cash crops $(29 \%)$ or beef cattle $(22 \%)$. On the other hand, farmers making goat cheeses on-farm produce less milk and are mainly located in the south of France. Half are dairy specialized, whereas the other half raise dairy goats together with dairy cattle (14\%), cash crops (11\%), or beef cattle $(8 \%)$.

In the French dairy goat sector, milk production is the main source of income, contributing enormously to gross income (from 90 to 93\%). Composition of production costs vary substantially with type of farm. For farmers who deliver milk to dairy industries, the largest cost is goat feeding (49\%), whereas for those who make 
cheese on-farm, labor accounts for the greatest cost (47\%; IDELE, 2017).

The average price of goat milk paid to farmers by the dairy industry increased by $35 \%$ in the last decade (i.e., from $€ 0.514 / \mathrm{L}$ in 2004 to $€ 0.695 / \mathrm{L}$ in 2015 ; IDELE, 2017), with the estimated break-even point being $€ 0.85 / \mathrm{L}$ for farms that deliver milk to dairy enterprises and $€ 2.96 / \mathrm{L}$ for on-farm cheese makers. Most milk $(78 \%)$ is processed into cheese or yogurt by dairy industries. However, on-farm cheese production is also important, accounting for $22 \%$ of French goat milk production. The PDO goat-milk cheeses represent $7 \%$ of goat-milk cheese production in France (Creusat et al., 2015), where 14 PDO goat-milk cheeses are currently produced (e.g., Sainte Maure de Touraine, Rocamadour, Selles sur Cher, and Chavignol cheeses). In total, $18 \%$ of the goat-milk cheese produced in France is exported (Bossis et al., 2017).

\section{Greece}

From 2013 to 2015 (average data), goat milk accounted for $3.4 \%$ of the TAO and $22 \%$ of the LO in Greece (ELOGAK, 2017; ELSTAT, 2017), which has the largest dairy goat population (2.4 million) among FGIS as well as in the EU, with a moderate degree of dairy specialization ( $87 \%$ of the farms; Table 5 ). Milk production by the Greek goat sector is also the greatest in the EU (Table 5), but of the 600.0 kt produced, only $21 \%$ is delivered to dairy industries. The rest of the milk is used for on-farm cheese production, mostly sold directly to consumers and, for this reason, difficult to quantify.

In Greece, dairy goat production systems are generally more extensive than those used for dairy sheep, using in most cases rangelands that are not appropriate for rearing other livestock species (Gelasakis et al., 2017). Consequently, average milk yield is low (250 L/ doe; Table 5).

Most Greek dairy goats are crossbred from local breeds with imported breeds such as Damascus, Alpine, or Saanen. The only important purebreed is Skopelos from Skopelos Island in the Aegean Sea, whose population of 7,250 goats yields, on average, $239 \mathrm{~L} /$ doe (Kominakis et al., 2000).

Farms are, on average, mid-sized (160 does/farm; Table 5) and generally located in remote, mountainous, and less-favored lands (Arsenos et al., 2014) unsuitable for grazing other species and critical for rural populations. In these places, the rural economy is poorly diversified and employment opportunities are limited. Therefore, dairy goats offer rural families an opportunity to increase their income and use family labor more intensively (Theodoridis et al., 2014). This role was very important during the last economic crisis, but the maintenance of financial support to goat farmers who use rangelands is not ensured within the new Common Agricultural Policy, a fact that threatens the viability of the Greek goat sector.

Today, the dairy goat sector is gaining attention in Greece, and current market opportunities include pasteurization of raw goat milk as well as production of PDO Feta sheep-goat milk cheese and pure goat-milk cheeses of great local importance.

Labor costs account for a large share of the total production cost in Greek dairy goat farms, whereas feeding costs (i.e., purchased and on-farm produced feedstuff) are low because they are based on grazing. Averaged goat milk price was $€ 0.60 / \mathrm{L}$ in 2016 and has not varied substantially in Greece over the last few years. The break-even point was not calculated for Greek dairy goat farms because of the lack of data and the considerable diversity of production systems.

\section{Italy}

In Italy, goat milk accounted for $0.2 \%$ of the TAO and $0.7 \%$ of the LO for the 2013 to 2015 period (ISTAT, 2017a,b), and dairy goats (0.75 million head and $94 \%$ of total goat population; Table 5) are mainly reared in extensive or semi-intensive systems. Farm size is, on average, very small (36 does; Table 5), and most dairy goats are reared in Sicily $(26.0 \%)$ and Sardinia $(21.5 \%)$, with Piemonte, Lombardy, and Veneto together accounting for $22.2 \%$ of the total.

Italian goat milk production (115.2 kt) and doe yield (153 L/doe) are the lowest among FGIS (Table 5), with $28.8 \%$ of goat milk being processed in dairy industries (Assolatte, 2017; ISTAT, 2017a). Goat milk is mainly processed in Sardinia (48.2\%), followed by Piemonte, Lombardy, and Veneto (together 33.3\%), and Lazio $(6.9 \%)$.

The main dairy goat breeds reared in Italy are local: Sarda (33\%; 201 L/doe) in Sardinia; Derivata Siria (8\%; $316 \mathrm{~L} /$ doe) mainly located in southern Italy; Orobica (1.3\%; $296 \mathrm{~L} /$ doe) in Lombardy; and Girgentana (1.2\%; $240 \mathrm{~L} /$ doe) in Sicily.

The number of does and the amount of goat milk transformed by the Italian dairy industry have shown different patterns over time (ISTAT, 2017a). The number of does tended to decrease from 2002 to 2015 (on average, $-0.7 \% / \mathrm{yr}$ ) but showed a maximum in 2010 (0.83 million) and a minimum in 2012 (0.73 million). In contrast, the amount of goat milk transformed by the dairy industry increased over time (on average, 8.1\%/ yr), from $16.0 \mathrm{kt}$ in 2002 to $33.1 \mathrm{kt}$ in 2015 .

The price of goat milk in Italy has not varied substantially over time, showing a slight increase from $€ 0.66 / \mathrm{L}$ 
in 2014 to $€ 0.77 / \mathrm{L}$ in 2016 , and then decreasing to $€ 0.65 / \mathrm{L}$ in 2017 . No break-even point was calculated for Italian dairy goat farms because of the lack of data and the great diversity of production systems.

\section{Spain}

Goat milk accounted for $0.7 \%$ of the TAO and $2.0 \%$ of the LO in Spain in the 2013 to 2015 period (MAPAMA, 2016b), which is approximately two-thirds of the sheep milk contribution. Nevertheless, more than half of Spanish goats (57\%; Table 5) are dairy goats, which produce annually $466.6 \mathrm{kt}$ of milk, with the remainder intended for kid production (MAPAMA, 2016a). This amount of milk places Spain in third position in the EU and among FGIS, and in second position in milk yield per doe (Table 5).

Most Spanish goat milk $(80.9 \%)$ is produced in 3 communities of southern Spain (Andalucia, 42.8\%; Castilla-La Mancha, 17.0\%; Murcia, 9.4\%) and in the Canary Islands (11.7\%; MAPAMA, 2016a), where it plays an important environmental, sociological, and economic role.

Among Spanish goat farms, $71 \%$ are specialized in dairy production, and the remainder are dual-purpose (milk and kid production; MAPAMA, 2016b). Farm size is small (64 does; Table 5), on average, but very heterogeneous. The fact that $87.1 \%$ of goat milk is produced in $33 \%$ of the farms demonstrates the high degree of dairy specialization that exists in these farms. As previously discussed for dairy sheep, the number of dairy goats decreased by $30.7 \%$ during the last decade although the total amount of goat milk remained steady due to an increase in individual milk yield (422 L/doe; Table 5) among local goat breeds (MAPAMA, 2016a). Moreover, there is strong evidence of intensification of traditional Spanish dairy goat production systems associated with increases in herd size, lactation length, investment in facilities, and improvement in health and management (Castel et al., 2011), as well as a decrease in grazing. In most cases, modernized farms coexist with those that maintain semi-extensive systems with traditional management practices (Gaspar et al., 2011) but without a significant effect of foreign breeds. High-yielding goat breeds from southern Spain are Florida (497 L/doe), Malagueña (464 L/doe), Murciano-Granadina (477 L/ doe), Payoya (314 L/doe), and those of the Canary Islands (i.e., Majorera, Palmera, and Tinerfeña; 379 to $488 \mathrm{~L} /$ doe). These breeds are reared in Spain under intensive or semi-intensive systems, depending on genetic merit, feeding, management, and facilities.

Goat milk prices in Spain are usually lower than those of sheep milk but, similarly, have changed dramatically over time, increasing $27.5 \%$ from 2004 to 2016 (from $€ 0.483 / \mathrm{L}$ to $€ 0.616 / \mathrm{L}$ ), with a peak of $€ 0.750 / \mathrm{L}$ in 2015 (MAPAMA, 2016a). No break-even point was calculated for Spanish dairy goat farms because of the lack of data and the wide diversity of the production systems used.

Most Spanish goat milk (90.8\%; MAPAMA, 2016a) is transformed into cheese in large dairy industries, which coexist with small local industries and artisanal farm dairies (home consumption, 7.5\%; direct sales, 1.7\%; MAPAMA, 2016a). Pasteurized and sterilized liquid goat milk are new options for Spanish niche consumers (e.g., organic and allergic) but are currently negligible contributors to the total.

The production of pure goat-milk cheese in Spain is $47.6 \mathrm{kt}$, accounting for $25 \%$ of total pure goat-milk cheese in the EU (MAPAMA, 2016b) and surpassed only by French goat-milk cheeses. Despite this, per capita goat cheese consumption is currently very low $(0.27$ $\mathrm{kg} /$ inhabitant) in Spain. There are 7 PDO goat-milk cheeses in Spain, accounting for only $2.7 \%$ of total goatmilk cheeses, as follows: Murcia al Vino (43.4\%) and Murcia (4\%) from Murcia; Majorero (31.7\%), Palmero $(9.4 \%)$, and Flor de Guía $(<1 \%)$ from the Canary Islands; Ibores (8.6\%) from Extremadura; and Camerano (2.9\%) from Rioja. Approximately $41 \%$ of PDO goatmilk cheeses produced in Spain are exported, mainly outside the EU, with considerable sales of Murcia al Vino in the US market.

\section{STRATEGIES FOR IMPROVEMENT IN FGIS}

The dairy small ruminant sectors account for a minor part of the agricultural economies of France, Italy, and Spain $(0.9,0.9$, and $1.8 \%$ of the TAO, respectively) and a more relevant part in Greece (8.8\% of the TAO). These values are a result of the inverse relationship of the dairy sheep and goat industries with country income and are related to the availability of resources for other types of agricultural production. Nevertheless, these values also indicate a certain diversity among FGIS and the importance of the socio-cultural characteristics and local traditions related to food supply and traditional diets.

Overall, the FGIS dairy sheep industry has the highest specialization in Greece and Italy (93 and $75 \%$ of sheep, respectively), followed by France and Spain (30 and $21 \%$ of sheep, respectively). Dairy sheep are concentrated in a few specific regions of each country and based on local and crossbred or imported sheep breeds, which are mainly raised under semi-intensive and intensive systems. The size of dairy sheep flocks varies from small (140 to 161 ewes/farm) in Greece, Italy, and Spain to medium in France (333 ewes/farm). The yield of the ewes varies from low $(85$ and $101 \mathrm{~L} /$ ewe 
in Italy and Greece, respectively) to medium (165 and 216 L/ewe in France and Spain, respectively), showing substantial room for improvement. By comparing the break-even points and sheep milk prices previously reported, we note that most dairy sheep farms in France and Greece are working under the profitability threshold, whereas in Italy price is aligned with the cost, on average, but with large fluctuations among years and high variability among farms. Only in the intensive Chios farms in Greece is there enough margin for profit. In Spain, profitable farms coexist with others that are below the limit of profitability. In general, most sheep milk is sold to dairy industries to be processed into traditional cheese types, highly appreciated by the local markets, and many of them are sold as quality PDO sheep-cheeses for gourmet and export markets (e.g., Pecorino, Manchego, and Roquefort).

Dairy goats are produced in wider regions across FGIS, being based mainly on local breeds and raised under more extensive and transhumant systems than dairy sheep. Dairy goat specialization varies dramatically among FGIS, being high in France, Greece, and Italy (from 87 to $94 \%$ of total goats) and medium in Spain (57\%). Size of dairy goat herds is smaller than dairy sheep herds and varies from small (36 and 64 does/farm in Italy and Spain, respectively) to medium (160 and 190 does/farm in Greece and France, respectively). Milk yield is greater than in sheep and not related to specialization or farm size, varying from medium (153 and $250 \mathrm{~L} /$ doe in Italy and Greece, respectively) to high (422 and $589 \mathrm{~L} /$ doe in Spain and France, respectively), again showing room for improvement. Moreover, compared with sheep milk, goat milk is often processed on the farm into different local dairy products, including yogurt, and is mainly addressed to local or national markets. Nevertheless, PDO goat-milk cheeses produced by dairy industries (e.g., Murcia al Vino) are exported, and goat milk is currently pasteurized or sterilized for direct human consumption (i.e., liquid milk) or dehydrated for exportation as skim milk powder. In contrast, fluid sheep milk is rarely commercialized. Mixed sheep-goat milk cheeses (e.g., Feta) and cow-sheep-goat milk cheeses (e.g., Mezcla and Cabrales) are common in many countries (e.g., Greece and Spain) and appreciated in local and export markets.

Some of the main characteristics of FGIS can be considered as interesting perspectives for the future development of their dairy sheep and goat sectors. For example, France is improving the efficiency of dairy sheep and goat farms by increasing milk yield per animal, thus maintaining the share of French cheese in the international market. In Italy, the dairy sheep and goat sectors are pushed by the processing industries toward increasing the amount of milk transformed out of the farm and destined for the international market. In Spain, the level of dairy specialization and size of sheep and goat farms have increased with the increase in milk yield per animal and total milk production of the intensive farms, pushed by favorable milk prices. As a result, the small and less technological farms tended to disappear in Spain.

To further develop the dairy sheep and goat industries in FGIS, considered as key countries, several strategic priorities should be taken into account, as summarized in Table 6. In France, dairy sheep and goat sectors need to adapt their production to market requirements, especially regarding the growth of the market of fresh products. A first priority for the French dairy sheep sector is to increase the milk intended for PDO sheepmilk cheese-making. This evolution requires a change in milking season schedule, by beginning earlier in autumn and continuing during summer. At the same time, it would be necessary to adapt the production techniques, taking into consideration future changes (e.g., price volatility and climatic hazards), while allowing breeders' living conditions to improve and stimulating generational renewal in France.

Greece has suffered from the recent economic crisis and the dairy sheep and goat sectors have shown a delay in restructuring compared with the other FGIS countries. Nevertheless, extensive farms proved to be more resilient and the designation of appropriate land use is critical for support of the current extensive, grazing-based production systems. Market-oriented promotion strategies and certified products need to be developed to improve the overall economic resilience of the sector. Another strategic priority that may improve the efficiency of the Greek goat sector is the use of modern milking and reproduction practices, which is especially important for intensive farms, which depend heavily on fixed capital. However, the development of the whole sector is also linked to valorization of local breeds, which are reared under extensive production systems. The overall social, economic, and environmental sustainability of the sheep and goat sector in Greece depends on the design and implementation of breeding programs for local sheep and goat breeds and on the development of unique pasture-raised related products that could strengthen the food value chain that they support.

Italy is losing market share of Pecorino Romano cheese because of politics and the fact that it has only one main importer (i.e., the United States), with consequent problems related to low milk prices and competitiveness of sheep farms. One of the most important actions to mitigate the decline of the Italian dairy sheep industry would be to regulate the production of PDO Pecorino Romano to protect farmers 
INVITED REVIEW: DAIRY SHEEP AND GOAT SECTORS

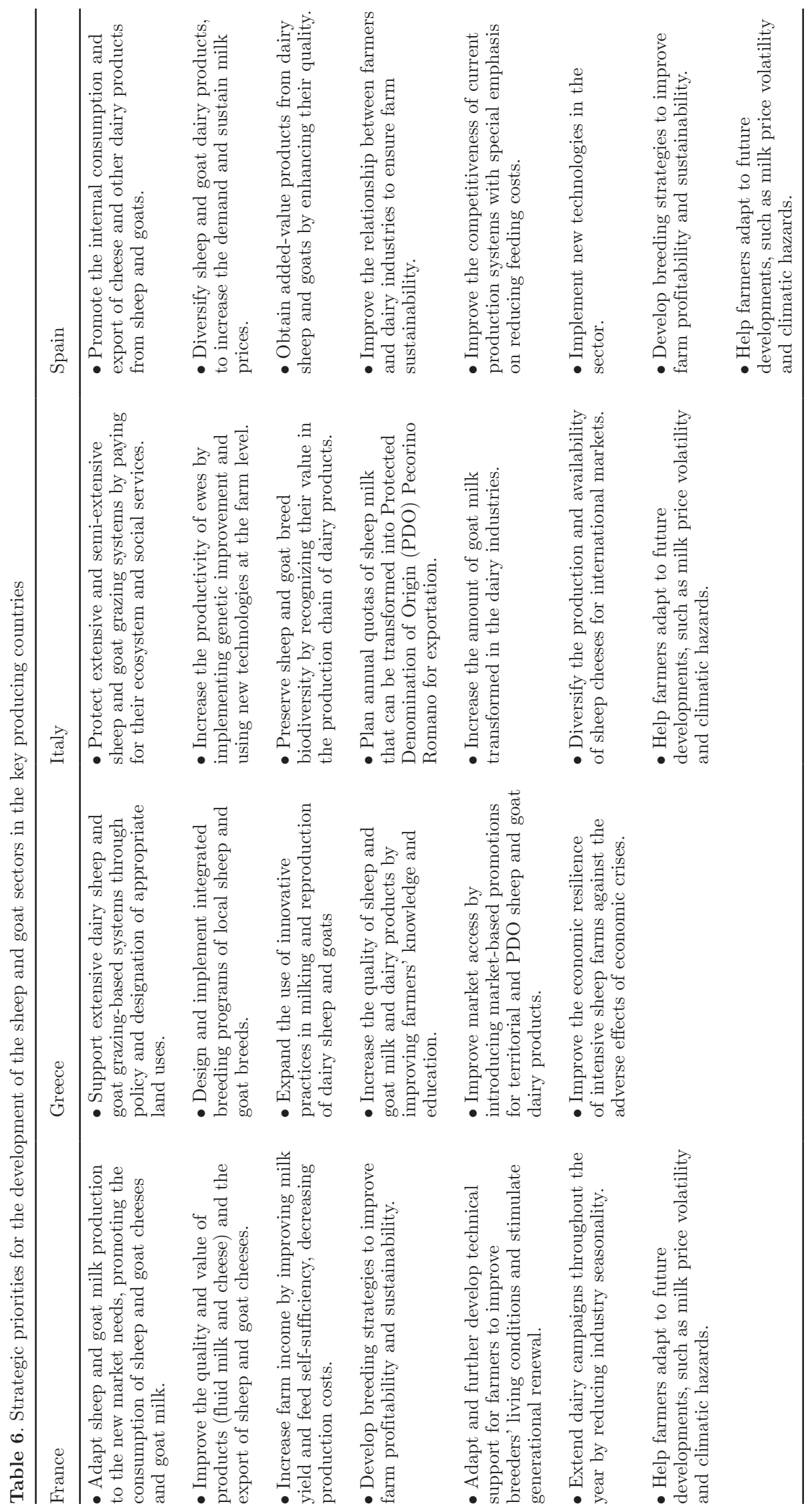

Journal of Dairy Science Vol. 101 No. 8, 2018 
from dramatic milk price fluctuations, which seriously compromise their profitability. On the other hand, a market-oriented diversification of dairy sheep products, with improved farm efficiency, could maintain the current milk production and warrant work and well-being in rural areas subjected to depopulation. The Italian dairy goat sector has been continuously increasing, and the predicted increase in market space and the desired diversity of dairy products may be achieved by promoting local specialties, which are key for the further development of the goat dairy industry.

In Spain, the dairy sheep and goat sectors are growing rapidly because of strong modernization of the sector, with considerable increases in total milk production and individual milk yield. Spanish small ruminant dairy products are gaining new market share in the world. Nevertheless, production costs need to be decreased and farm profitability improved, especially to cope with the recent decrease in milk prices, which indicates that this sector may be suffering a period of adjustment. Moreover, the internal consumption of sheep and goat cheeses needs to be promoted, and diversified and value-added dairy products for new markets need to be identified. All of these concepts need to be addressed under mechanisms that guarantee the overall sustainability of the farms (i.e., economic, environmental, and social).

\section{CONCLUSIONS}

The dairy small ruminant sector consists of a large number of sheep and goats worldwide, although their milk represents only a minor part of world milk production. Nevertheless, the production of small ruminant milk is concentrated in countries in which it is strongly related to sociocultural aspects and resource availability. Most dairy sheep and goat production systems are environmentally friendly and play a key role in developing rural communities. The current production situation shows substantial room for improvement, and relevant increases in milk production (from 30 to 50\%) are expected by 2030. Four countries-France, Greece, Italy, and Spain - stand out in the dairy sheep and goat worldview and lead the international market for sheep and goat dairy products. These countries have characteristic productive models based on the use of specific breeds and PDO cheeses produced according to traditional recipes and currently appreciated as ingredients of healthy diets. Break-even analysis showed that many production systems in these 4 countries are below the threshold of profitability. For this reason, the amount of milk produced and the milk price paid by the dairy industries to the farmers need adjustments to warrant the sustainability of the dairy small ruminant farms in the future. With this aim, the reinforcement of traditional PDO cheeses as well as the development of new dairy products (i.e., niche and ethnic foods) may be of interest. Special attention should be paid to applied and innovative research to adapt the sheep and goat sectors to future production and market trends.

\section{ACKNOWLEDGMENTS}

This research was orally presented at the Small Ruminant Symposium: New Opportunities for Dairy Sheep and Goats, a symposium of the 2017 American Dairy Science Association Annual Meeting held in Pittsburgh, Pennsylvania, and was supported, in part, by the European Federation of Animal Science (Rome, Italy).

\section{REFERENCES}

Arsenos, G., A. Gelasakis, S. Pinopoulos, R. Giannakou, and I. Amarantidis. 2014. Description and typology of dairy goat farms in Greece. Pages 571-574 in Proc. 4th ISOFAR Scientific Conference, Istanbul, Turkey. International Society of Organic Agriculture Research, Trenthorst, Germany.

Assolatte. 2017. Associazione Italiana Lattiero Casearia. Accessed May 2, 2017. http://www.assolatte.it/.

Barillet, F., G. Lagriffoul, P. G. Marnet, H. Larroque, R. Rupp, D. Portes, F. Bocquier, and J. M. Astruc. 2016. Objectifs de sélection et stratégie raisonnée de mise en œuvre à l'échelle des populations de brebis laitières françaises. INRA Prod. Anim. 29:19-40.

Bellet, V., M. Carlier, P. Chotteau, G. Milet, E. Morin, B. Rubin, and G. You. 2017. Dossier Annuel Ovins: l'Élevage Ovin, Facteur de Résilience. Dossier Économie de l'Élevage, No. 478, Institut de l'Élevage, Paris, France.

Bossis, N., S. Bouyssiere, P. Chotteau, B. Rubin, and G. You. 2017. Dossier annuel caprins: 2016, une situation favorable... 2017, une nécessaire relance des installations. Dossier Économie de l'Élevage, No. 477, Institut de l'Élevage, Paris, France.

Caja, G. 1990. L'évolution des systèmes de production ovin-lait dans le Bassin Méditerranéen. Opt. Médit. A 12:31-38.

Castel, J. M., Y. Mena, F. A. Ruiz, J. Camúñez-Ruiz, and M. SánchezRodríguez. 2011. Changes occurring in dairy goat production systems in less favoured areas of Spain. Small Rumin. Res. 96:83-92.

Champion, F., A. Mottet, E. Morin, C. Perrot, A.-C. Dockès, D. Neumeister, and G. Lagriffoul. 2013. Bergers Demain en Brebis Laitières: Étude sur la Production Ovine Laitière à l'Horizon 2020: Éléments de Diagnostic et Propositions d'Actions. Collection Résultats, Institut de l'Elevage, Paris, France.

Creusat, C., T. Smadja, L. Forray, P. Zindy, C. Bossu, and B. Roney. 2015. Chiffres Clés 2014 des Produits sous Signes de la Qualité et de l'Origine. Produits laitiers AOP. INAO-CNAOL, Institut National de l'Origine et de la Qualité, Paris, France.

Dennett, C. 2016. Key ingredients of the Mediterranean diet: The nutritious sum of delicious parts. Today's Dietitian 18:28-33.

ELOGAK. 2017. Greek Milk Board statistics. Accessed Mar. 22, 2017. http://www.elogak.gr.

ELSTAT. 2017. Livestock capital and production. Accessed Feb. 13, 2018. http://www.statistics.gr/el/statistics/-/publication/ SPK33/-.

FAOSTAT (Food and Agriculture Organization of the United Nations). 2018. Statistics database. Accessed Feb. 2, 2018. http:// www.fao.org/faostat/en/\#data.

Gaspar, P., A. J. Escribano, F. J. Mesías, M. Escribano, and A. F. Pulido. 2011. Goat systems of Villuercas-Ibores area in SW Spain: 
Problems and perspectives of traditional farming systems. Small Rumin. Res. 97:1-11.

Gelasakis, A., G. Rose, R. Giannakou, G. E. Valergakis, A. Theodoridis, P. Fortomaris, and G. Arsenos. 2017. Typology and characteristics of dairy goat production systems in Greece. Livest. Sci. 197:22-29.

ICAR (International Committee for Animal Recording). 2018a. Results for the years 2012-2013. Yearly enquiry on the situation of sheep milk recording in ICAR member countries. Accessed Feb. 2, 2018. http://www.icar.org/wp-content/uploads/2015/08/Sheep -Survey-2012-2013.pdf.

ICAR (International Committee for Animal Recording). 2018b. Results for the years 2012-2013. Yearly enquiry on the situation of goat milk recording in ICAR member countries. Accessed Feb. 2, 2018. http://www.icar.org/wp-content/uploads/2015/08/Goat -Survey-2012-2013.pdf.

IDELE. 2016a. Chiffres Clés 2016 Productions Ovines Lait et Viande. Institut de l'Élevage et de la CNE, Paris.

IDELE. 2016b. Chiffres Clés 2016 Productions Caprines Lait et Viande. Institut de l'Élevage et de la CNE, Paris.

IDELE. 2017. Observatoire Inosys-Réseaux d'élevage. Accessed May 2, 2017. http://idele.fr/domaines-techniques/economie/revenu-de -lexploitation/publication/idelesolr/recommends/lobservatoire -inosys-reseaux-delevage-est-en-ligne.html.

INSEE. 2018. Les comptes prévisionnels de l'agriculture pour 2017 Accessed Feb. 13, 2018. https://www.insee.fr/fr/statistiques/ 3286347 \#tableau-figure1.

ISMEA. 2017. Latte e derivati ovicaprini. Accessed Apr. 29, 2017. http://www.ismea.it/istituto-di-servizi-per-il-mercato-agricolo -alimentare.

ISTAT. 2017a. Agricoltura e zootecnia. Accessed Jan 22, 2017. http:// www.istat.it/it/.

ISTAT. 2017b. L'andamento dell'economia agricola. Anno 2016. Accessed Dec. 29, 2017. http://www.istat.it/it/files/2017/05/ Andamento-economia-agricola-2016.pdf?title=Andamento + dell \% $2 \% 80 \% 99$ economia+agricola $+-+19 / \mathrm{mag} / 2017+-$.

Karras, A. 2017. Awassi USA. Accessed Jun. 21, 2017. http:// karrasfarm.com/sheep/awassi-sheep/.

Kominakis, A., A. L. Hager-Theodorides, A. Saridaki, G. Antonakos, and G. Tsiamis. 2017. Genome-wide population structure and evolutionary history of the Frizarta dairy sheep. Animal 11:1680-1688.

Kominakis, A., E. Rogdakis, Ch. Vasiloudis, and O. Liaskos. 2000. Genetic and environmental sources of variation of milk yield of Skopelos dairy goats. Small Rumin. Res. 36:1-5.

MAAF. 2017. Production de lait et utilization à la ferme - sourveilles séries à partir de 2000. Ministère de l'Agriculture et de
l'Alimentation et de la Forèt. Accessed May 2, 2017 https://stats .agriculture.gouv.fr/disar/\#.

Mantecón, A. R., P. Díez, B. Villadangos, Y. Martínez, and P. Lavín. 2009. Dairy sheep production systems at the central-north of Spain: Limiting factors. Opt. Médit. A 91:75-78.

MAPAMA. 2016a. Anuario de estadística agroalimentaria. Ministerio de Agricultura y Pesca, Alimentación y Medio Ambiente. Madrid (España). Accessed Apr. 20, 2017. http://www.mapama.gob.es/ estadistica/pags/anuario/2015/AE15.pdf.

MAPAMA. 2016b. El sector del ovino y caprino de leche en cifras. Principales indicadores económicos. Accessed May 3, 2017. http://www.mapama.gob.es/es/ ganaderia/temas/produccion-y-mercados-ganaderos/ indicadoreseconomicosdelsectorovinoycaprinodeleche2015_tcm7 -439813.pdf.

Meisegeier, L. 2013. The Awassi sheep in the USA. Pages 26-28 in Proc. 61st Annual Spooner Sheep Day, Spooner, WI. Department of Animal Science, University of Wisconsin-Madison, Madison, WI

Milán, M. J., G. Caja, R. González-González, A. M. Fernández-Pérez, and X. Such. 2011. Structure and performance of Awassi and Assaf dairy sheep farms in northwestern Spain. J. Dairy Sci. 94:771-784.

Milán, M. J., F. Frendi, R. González-González, and G. Caja. 2014 Cost structure and profitability of Assaf dairy sheep farms in Spain. J. Dairy Sci. 97:5239-5249.

Perrot, C., G. Barbin, N. Bossis, F. Champion, B. Morhain, and E. Morin. 2013. L'Élevage d'Herbivores au Recensement Agricole 2010. Cheptels, Exploitations, Productions. Dossier Économie de l'Élevage, No. 440-441, Institut de l'Élevage, Paris, France.

Ragkos, A., A. Siasiou, K. Galanopoulos, and V. Lagka. 2014. Mountainous grasslands sustaining traditional livestock systems: The economic performance of sheep and goat transhumance in Greece. Opt. Médit. A 109:575-579.

Theodoridis, A., A. Ragkos, D. Roustemis, G. Arsenos, Z. Abas, and E. Sinapis. 2014. Technical indicators of economic performance in dairy sheep farming. Animal 8:133-140.

Thomas, D. L., Y. M. Berger, B. C. McKusick, and C. M. Mikolayunas. 2014. Dairy sheep production research at the University of Wisconsin-Madison, USA-A review. J. Anim. Sci. Biotechnol. $5: 22-33$.

Ugarte, E., R. Ruiz, D. Gabiña, and I. H. Beltrán. 2001. Impact of high-yielding foreign breeds on the Spanish dairy sheep industry. Livest. Prod. Sci. 71:3-10.

USDA-FAS (Foreign Agricultural Service). 2016. Data and analysis. Accessed May 30, 2017. https://www.fas.usda.gov/data. 